TITLE:

\title{
Silver-catalyzed cross-coupling reactions of alkyl bromides with alkyl or aryl Grignard reagents
}

\section{$\operatorname{AUTHOR}(\mathrm{S}):$}

Someya, Hidenori; Yorimitsu, Hideki; Oshima, Koichiro

\section{CITATION:}

Someya, Hidenori ... [et al]. Silver-catalyzed cross-coupling reactions of alkyl bromides with alkyl or aryl Grignard reagents. Tetrahedron Letters 2009, 50(26): 3270-3272

\section{ISSUE DATE:}

2009-07-01

URL:

http://hdl.handle.net/2433/123412

\section{RIGHT:}

Copyright (C) 2009 Elsevier; This is not the published version. Please cite only the published version.; この論文は出版社版でありません。引用の 際には出版社版をご確認ご利用ください。 


\section{Graphical Abstract}

To create your abstract, type over the instructions in the template box below.

Fonts or abstract dimensions should not be changed or altered.

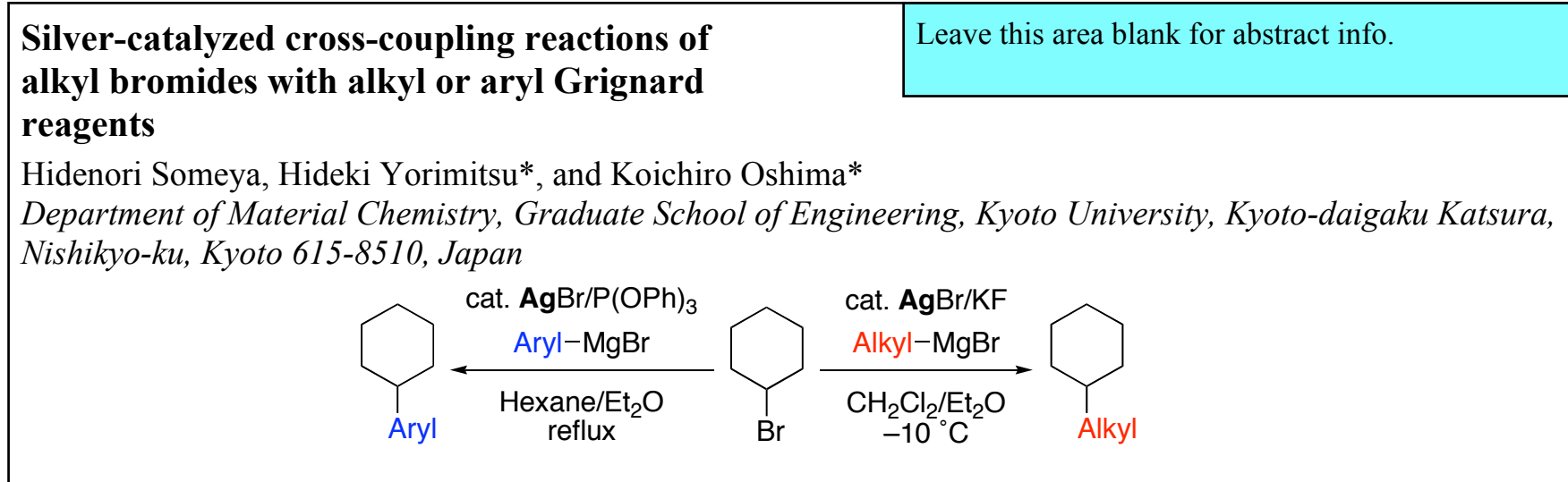




\title{
Silver-catalyzed cross-coupling reactions of alkyl bromides with alkyl or aryl Grignard reagents
}

\author{
Hidenori Someya, Hideki Yorimitsu ${ }^{*}$, and Koichiro Oshima ${ }^{*}$ \\ Department of Material Chemistry, Graduate School of Engineering, Kyoto University, Kyoto-daigaku Katsura, Nishikyo-ku, Kyoto 615- \\ 8510, Japan
}

\begin{abstract}
Treatment of secondary or tertiary alkyl bromides with alkyl Grignard reagents in the presence of catalytic amounts of silver bromide and potassium fluoride in $\mathrm{CH}_{2} \mathrm{Cl}_{2}$ afforded the corresponding cross-coupling products in reasonable yields. Moreover, silver showed catalytic activity for the cross-coupling reactions of alkyl bromides with aryl Grignard reagents. (C) 2010 Elsevier Science. All rights reserved
\end{abstract}

Transition-metal-catalyzed cross-coupling reactions of alkyl halides with Grignard reagents are very useful methods for carbon-carbon bond formation in organic synthesis. ${ }^{1}$ Among them, the use of unactivated secondary or tertiary alkyl halides as substrates is more difficult than that of primary alkyl halides, due to the faster $\beta$-hydride elimination from the corresponding alkyl transition-metal intermediates. Recently, the cross-coupling reactions of unactivated secondary alkyl halides with aryl, ${ }^{2}$ alkenyl, ${ }^{3}$ or alkynyl $^{3 a}$ Grignard reagents have been achieved. However, the cross-coupling reactions of unactivated secondary alkyl halides with alkyl Grignard reagents are still rare, and have to be established. ${ }^{1,4}$

Recently, we have reported silver-catalyzed coupling reactions of alkyl halides with benzyl and allyl Grignard reagents. ${ }^{5}$ In these reactions, secondary and tertiary alkyl halides can be employed as substrates. Along the line of our studies on silver-catalyzed coupling reactions, here we wish to report silver-catalyzed cross-coupling reactions of alkyl bromides with alkyl or aryl Grignard reagents. ${ }^{6}$

Treatment of 2-bromooctane (1a) with 3phenylpropylmagnesium bromide in the presence of a catalytic amount of $\mathrm{AgCl}$ in $\mathrm{Et}_{2} \mathrm{O}$ afforded the crosscoupling product $\mathbf{2 a}$ in $34 \%$ yield (Table 1, entry 1 ). When we used $\mathrm{PdCl}_{2}, \mathrm{NiCl}_{2}, \mathrm{FeCl}_{3}$, or $\mathrm{CuCl}$ without any ligands instead of $\mathrm{AgCl}$, only trace amounts of $\mathbf{2 a}$ were detected. After optimizing reaction conditions, we found that $\mathrm{AgBr}$ was the most effective catalyst (entry 2). Using $\mathrm{CH}_{2} \mathrm{Cl}_{2}$ as a solvent improved the yield slightly (entry 3$){ }^{7}$ We thought that the low yields were due to the decomposition of alkylsilver intermediates at room temperature, because octane, propylbenzene, and allylbenzene were mainly produced. ${ }^{8,9}$ Indeed, the better yield was achieved at -10 ${ }^{\circ} \mathrm{C}$ (entry 4). The reaction in entry 4 showed poor reproducibility. When $10 \mathrm{~mol} \% \mathrm{KF}$ was added, we could reproduce the result and obtain the corresponding coupling product $2 \mathbf{a}$ in $68 \%$ yield (entry 5). AgF was not effective (entry 6). ${ }^{10}$ Even though both $\mathrm{AgF}$ and $\mathrm{LiBr}$ were added, the product 2a was obtained in only $23 \%$ yield (entry 7 ). Although the role of KF is not clear at this stage, KF would dissociate the aggregation of $\mathrm{AgBr}$ or stabilize alkylsilver intermediates by coordination to the silver metal. ${ }^{11}$

The silver-catalyzed alkylation reactions (10 mol \% $\mathrm{AgBr} / \mathrm{KF}$ ) of various substrates are summarized in Table $2{ }^{12}$ Both cyclic and acyclic secondary alkyl bromides underwent the alkylation reactions (Table 2, entries 1-4). The reaction of tertiary alkyl halide 1e suffered from a moderate yield (entry 5). In this case, 2-methyldecane was mainly obtained. Although the reaction of 1bromoadamantane (1f) was slow, it resulted in a reasonable yield of $\mathbf{2 f}$ (entry 6). It is quite interesting that tertiary alkyl bromides can be used as reaction partners. ${ }^{1}$ The substrates having functional groups such as THP ether and sulfonamide could be also employed (entries 7 and 8). The

\footnotetext{
* Corresponding author. Tel.: +81-75-383-2441; fax: +81-75-383-2438; e-mail: yori@orgrxn.mbox.media.kyoto-u.ac.jp; oshima@orgrxn.mbox.media.kyoto-u.ac.jp .
} 
reaction of 1-bromooctane (1i) resulted in low yield (entry 9).

Table 1. Optimization of conditions

\begin{tabular}{|c|c|c|c|c|}
\hline \multirow{3}{*}{$\begin{array}{r}{ }^{n} \mathrm{C}_{6} \mathrm{H}_{13} \\
\mathbf{1 a} \\
\text { entry }\end{array}$} & \multicolumn{3}{|c|}{ Mtl (10 mol \%) } & \multirow[b]{2}{*}{$\mathrm{C}_{6} \mathrm{H}_{13}{ }_{2 \mathrm{a}}$} \\
\hline & 2.0 & & $15 \mathrm{~h}$ & \\
\hline & $\mathrm{Mtl}$ & solvent & temp. & yield $^{\mathrm{a}} / \%$ \\
\hline 1 & $\mathrm{AgCl}$ & $\mathrm{Et}_{2} \mathrm{O}$ & $25{ }^{\circ} \mathrm{C}$ & $34^{\mathrm{b}}$ \\
\hline 2 & $\mathrm{AgBr}$ & $\mathrm{Et}_{2} \mathrm{O}$ & $25^{\circ} \mathrm{C}$ & 45 \\
\hline 3 & $\mathrm{AgBr}$ & $\mathrm{CH}_{2} \mathrm{Cl}_{2}$ & $25^{\circ} \mathrm{C}$ & 47 \\
\hline 4 & $\mathrm{AgBr}$ & $\mathrm{CH}_{2} \mathrm{Cl}_{2}$ & $-10{ }^{\circ} \mathrm{C}$ & $44-62$ \\
\hline 5 & $\mathrm{AgBr} / \mathrm{KF}$ & $\mathrm{CH}_{2} \mathrm{Cl}_{2}$ & $-10{ }^{\circ} \mathrm{C}$ & 68 \\
\hline 6 & $\mathrm{AgF}$ & $\mathrm{CH}_{2} \mathrm{Cl}_{2}$ & $-10{ }^{\circ} \mathrm{C}$ & $<5^{\mathrm{c}}$ \\
\hline 7 & $\mathrm{AgF} / \mathrm{LiBr}$ & $\mathrm{CH}_{2} \mathrm{Cl}_{2}$ & $-10{ }^{\circ} \mathrm{C}$ & $23^{\mathrm{d}}$ \\
\hline
\end{tabular}

${ }^{\mathrm{a}}$ Based on NMR analysis. ${ }^{\mathrm{b}} 3 \%$ of $\mathbf{1 a}$ was recovered. ${ }^{\mathrm{c}} 26 \%$ of 1 a was recovered. ${ }^{\mathrm{d}} 11 \%$ of $1 \mathrm{a}$ was recovered.

Table 2. Silver-catalyzed alkylation of alkyl bromides ${ }^{\mathrm{a}}$

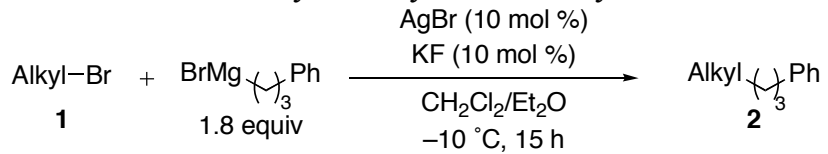

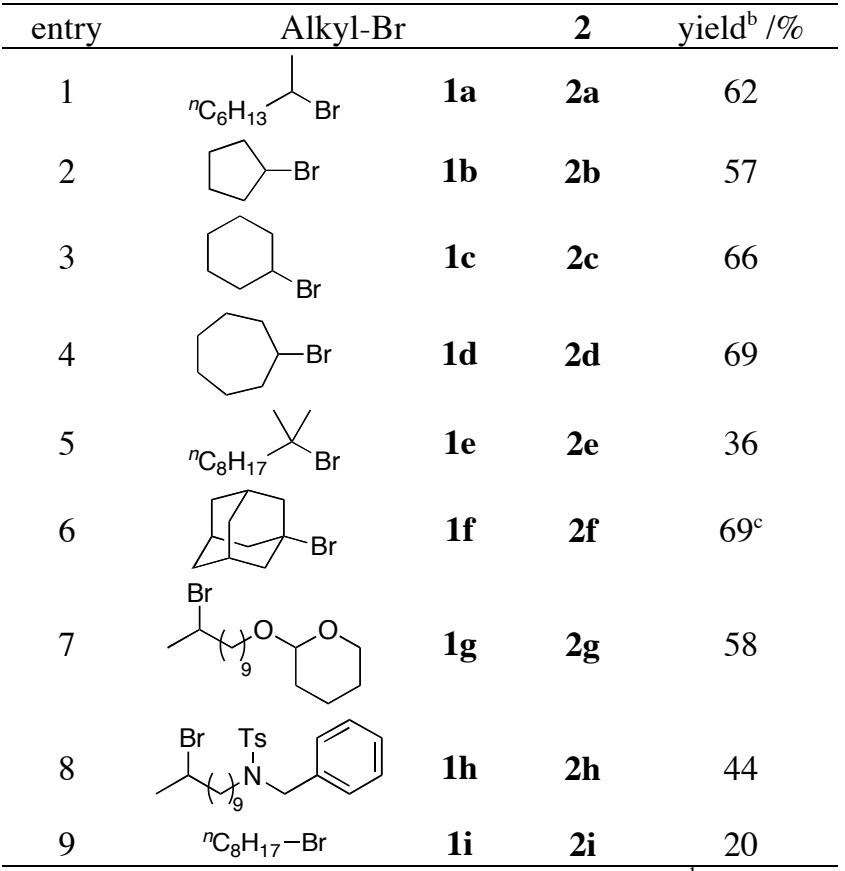

${ }^{\mathrm{a}}$ The Grignard reagent was $2.0 \mathrm{M} \mathrm{Et}_{2} \mathrm{O}$ solution. ${ }^{\mathrm{b}}$ Isolated yields. ${ }^{\mathrm{c}}$ Performed with 3.0 equiv of the Grignard reagent at $25{ }^{\circ} \mathrm{C}$ for $64 \mathrm{~h}$.

An alkyl Grignard reagent bearing a terminal alkene moiety reacted with secondary alkyl bromide 1d smoothly to afford $\mathbf{2 j}$ in $63 \%$ yield (Scheme 1). Although KF was added in this alkylation reaction, the reaction conditions were compatible with a tert-butyldimethylsiloxy group.
Unfortunately, the reactions with secondary and tertiary alkyl Grignard reagents afforded only trace amounts of the corresponding coupling products under these reaction conditions. $^{13}$

Scheme 1. Scope of alkyl Grignard reagents

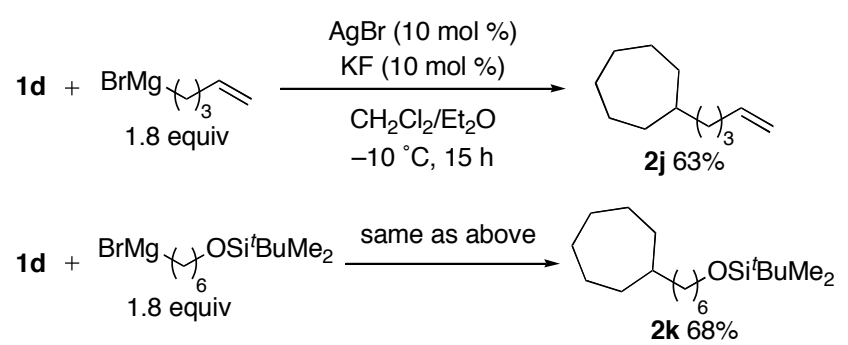

Next, we applied the silver catalysis to the cross-coupling reactions with phenyl Grignard reagent. Under the conditions with $\mathrm{KF}$, we could not obtain the phenylated product and the starting material was recovered. After reoptimization of reaction conditions, we found that treatment of bromocyclohexane (1c) with phenylmagnesium bromide in the presence of $10 \mathrm{~mol} \%$ $\mathrm{AgBr} / \mathrm{P}(\mathrm{OPh})_{3}$ in refluxing hexane afforded the crosscoupling product $3 \mathbf{c}$ in $81 \%$ yield (Table 3 , entry 2). ${ }^{14,15}$ Acyclic alkyl bromides as well as cyclic ones underwent the reactions (entry 1). The reaction of 1bromoadamantane (1f) took $10 \mathrm{~h}$ for completion (entry 3). Primary alkyl bromide 1i underwent the phenylation to give $3 \mathbf{i}$ in high yield (entry 4 ).

Table 3. Silver-catalyzed phenylation of alkyl bromides ${ }^{a}$

\begin{tabular}{|c|c|c|c|c|}
\hline $\begin{array}{c}\text { Alkyl-Br } \\
\mathbf{1}\end{array}$ & 1.6 equiv & $\begin{array}{r}\mathrm{AgBr} \\
\mathrm{OPPh} \\
\mathrm{He} \\
\mathrm{re}\end{array}$ & $\begin{array}{l}\mathrm{ol} \%) \\
\mathrm{mol} \%) \\
\mathrm{t}_{2} \mathrm{O} \\
\mathrm{h}\end{array}$ & Alkyl \\
\hline entry & Alkyl-Br & & 3 & yield $^{\mathrm{b}} / \%$ \\
\hline 1 & $26 \cdot 13$ & 1a & $3 \mathbf{a}$ & 63 \\
\hline 2 & & 1c & $3 c$ & 81 \\
\hline 3 & & 1f & 3f & $61^{\mathrm{c}}$ \\
\hline 4 & ${ }^{n} \mathrm{C}_{8} \mathrm{H}_{17}-\mathrm{Br}$ & $1 \mathbf{i}$ & $\mathbf{3 i}$ & 88 \\
\hline
\end{tabular}

${ }^{\mathrm{a}}$ The Grignard reagent was $1.0 \mathrm{M} \mathrm{Et}_{2} \mathrm{O}$ solution. ${ }^{\mathrm{b}}$ Isolated yields. ${ }^{\mathrm{c}}$ Performed for $10 \mathrm{~h}$.

$o$-Tolyl Grignard reagent can be also employed to afford the corresponding product 4 in $90 \%$ yield (Scheme 2 ).

Scheme 2. Reaction with $o$-tolyl Grignard reagent 


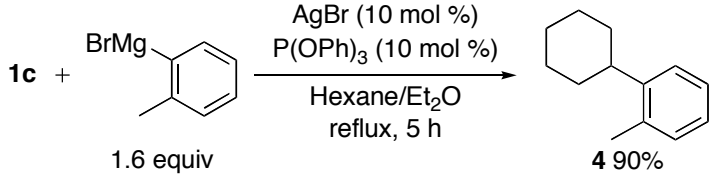

Treatment of 1,10-dibromoundecane (1j) with pentylmagnesium bromide under the $\mathrm{AgBr} / \mathrm{KF}$-catalyzed alkylation conditions afforded monoalkylated product $\mathbf{5} \mathbf{a}$ in $55 \%$ yield (Scheme 3 ). Dialkylated product $\mathbf{5 b}$ was not detected. The reaction of $\mathbf{1 j}$ with phenylmagnesium bromide under the $\mathrm{AgBr} / \mathrm{P}(\mathrm{OPh})_{3}$-catalyzed arylation conditions yielded monophenylated product $\mathbf{6 a}$ and diphenylated product $\mathbf{6 b}$ in $43 \%$ and $16 \%$ yields, respectively. The fact that secondary alkyl bromide reacted faster than primary one suggested that these reactions would involve the generation of the corresponding carbocation or carbon-centered radical intermediates from alkyl bromides.

Scheme 3. Comparison of the reactivities of primary and secondary alkyl bromides

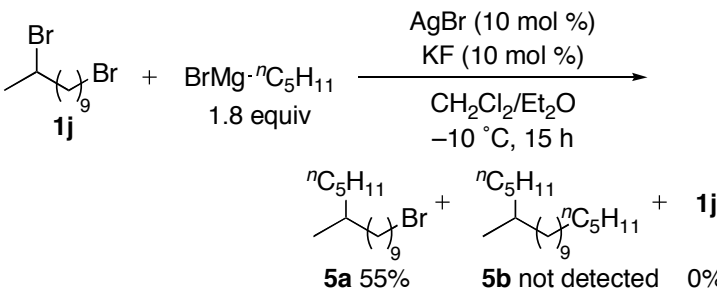

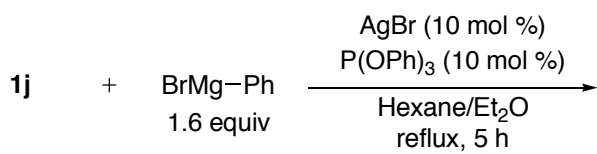

$$
\begin{aligned}
& \underbrace{\mathrm{Ph}}_{6 \mathbf{6} 43 \%} \mathrm{H}_{\mathbf{6 b} 16 \%}^{\mathrm{Br}}+\underbrace{\mathrm{Ph}}_{11 \%}
\end{aligned}
$$

In summary, we have developed the silver-catalyzed coupling reaction of alkyl bromides with alkyl or aryl Grignard reagents, where secondary and tertiary alkyl bromides can be used as substrates. The present results unveil the new catalytic potential of silver.

\section{Acknowledgments}

This work was supported by Grants-in-Aid for Scientific Research from the Ministry of Education, Culture, Sports, Science and Technology, Government of Japan. H.S. acknowledges JSPS for financial support.

\section{References}

1. (a) Frisch, A. C.; Beller, M. Angew. Chem. Int. Ed. 2005, 44, 674-688. (b) Terao, J.; Kambe, N. Acc. Chem. Res. 2008, 41, $1545-1554$.

2. (a) Martin, R.; Fürstner, A. Angew. Chem. Int. Ed. 2004, 43, 3955-3957. (b) Nakamura, M.; Matsuo, K.; Ito, S.; Nakamura, E. J. Am. Chem. Soc. 2004, 126, 3686-3687. (c) Ohmiya, H.; Yorimitsu, H.; Oshima, K. J. Am. Chem. Soc. 2006, 128, 1886-1889. (d) Cahiez, G.; Habiak, V.; Duplais, C.; Moyeux, A. Angew. Chem. Int. Ed. 2007, 46, 4364-4366. (e) Yasuda, S.; Yorimitsu, H.; Oshima, K. Bull. Chem. Soc. Jpn. 2008, 81, 287-290. (f) Cahiez, G.; Chaboche, C.; Duplais, C.; Moyeux, A. Org. Lett. 2009, 11, 277-280.

3. (a) Ohmiya, H.; Yorimitsu, H.; Oshima, K. Org. Lett. 2006, 8 , 3093-3096. (b) Guérinot, A.; Reymond, S.; Cossy, J. Angew. Chem. Int. Ed. 2007, 46, 6521-6524. (c) Cahiez, G.; Duplais, C.; Moyeux, A. Org. Lett. 2007, 9, 3253-3254.

4. (a) Terao, J.; Todo, H.; Begum, S. A.; Kuniyasu, H.; Kambe, N. Angew. Chem. Int. Ed. 2007, 46, 2086-2089. (b) Cahiez, G.; Chaboche, C.; Duplais, C.; Giulliani, A.; Moyeux, A. Adv. Synth. Catal. 2008, 350, 1484-1488.

5. Someya, H.; Ohmiya, H.; Yorimitsu, H.; Oshima, K. Org Lett. 2008, 10, 969-971.

6. Silver is an effective catalyst for the coupling reaction of alkyl Grignard reagent $\mathrm{R}^{1} \mathrm{MgX}$ with alkyl halide $\mathrm{R}^{2} \mathrm{MgX}$ when the alkyl groups are the same $\left(\mathrm{R}^{1}=\mathrm{R}^{2}\right)$. (a) Kochi, J. K. J. Organomet. Chem. 2002, 653, 11-19. (b) Tamura, M.; Kochi, J. K. Synthesis 1971, 303-305.

7. The reactions in hexane, toluene, ${ }^{i} \mathrm{Pr}_{2} \mathrm{O}$, and THF resulted in lower yields $(10-30 \%)$

8. Whitesides, G. M.; Bergbreiter, D. E.; Kendall, P. E. J. Am. Chem. Soc. 1974, 96, 2806-2813.

9. Alkylsilver intermediates would be generated from alkyl halides and/or alkyl Grignard reagents.

10. Hatakeyama, T.; Nakamura, M. J. Am. Chem. Soc. 2007, 129, 9844-9845.

11. Westmijze, H.; Kleijn, H.; Vermeer, P. J. Organometal. Chem. 1979, 172, 377-383.

12. We also detected alkenes and alkanes in these reactions. The alkanes were the main byproducts.

13. The reactions of 3-bromo-1-phenylbutane with cyclopentylmagnesium bromide and with tertbutylmagnesium bromide afforded the corresponding coupling products in $13 \%$ and $5 \%$ yields, respectively.

14. The reactions in $\mathrm{CH}_{2} \mathrm{Cl}_{2}, \mathrm{Et}_{2} \mathrm{O}$, and THF resulted in lower yields. The reaction in pentane resulted in a similar yield with a prolonged reaction time of $11 \mathrm{~h}$.

15. When pyridine, dppe, $\mathrm{P}(\mathrm{OMe})_{3}$, and $\mathrm{KF}$ were used as additives in refluxing hexane, $3 \mathrm{c}$ was obtained in $44 \%, 16 \%$, $54 \%$, and $56 \%$ yield, respectively. When no additive was used, $3 \mathbf{c}$ was obtained in $41 \%$ yield.

\section{Supplementary Material}

Experimental details, and characterization data of $\mathbf{1 g}, \mathbf{1 h}, \mathbf{1 j}$, and the products. Supplementary data associated with this article can be found in the online version. 